\title{
Formation of $X$ Phases and Origin of Grain Refinement Effect in Cu-Al-Ni Shape Memory Alloys Added with Titanium
}

\author{
Kenji ADACHI, Kazuo SHOJI and Yoichiro HAMADA \\ Central Research Laboratory, Sumitomo Metal Mining Co., Ltd., Nakakokubun, Ichikawa, Chiba-ken, 272 Japan.
}

(Received on August 11, 1988; accepted in the final form on October 14, 1988)

\begin{abstract}
Grain refinement effect in Ti-doped $\mathrm{Cu}-\mathrm{Al}-\mathrm{Ni}$ shape memory alloys has been studied using microscopic and microanalytical methods. Titanium is found to decrease as-cast grain size and reduce grain coarsening rate during betatization/homogenization heating but does not affect much on large grain refinement during hot working. A eutectic phase separation takes place during casting and Ti-rich eutectic equilibrates on subsequent heating to produce homogeneously distributed $\mu \mathrm{m}$-order $X_{L}$ particles at more than 0.38 mass $\% \mathrm{Ti}$ additions, whereas two-orders-ofmagnitude smaller $X_{S}$ phase tends to precipitate in the $\beta$ phase which has less than 0.05 mass $\%$ solid solubility of Ti.

The grain refinement upon casting is considered to originate from the constitutional supercooling effect and the reduced diffusion rate by presence of Ti. However, the ultimate refinement effect depends significantly on the pinning effect of $X_{S}$ which suppresses the growth of $\beta$ grains
\end{abstract}

KEY WORDS: grain refinement; shape memory alloy; copper-aluminum-nickel; titanium; dopant; $X$ phase; eutectic reaction; precipitate; pinning effect; ductility improvement; transmission electron microscopy.

\section{Introduction}

Grain refinement of Cu-based shape memory alloys is now regarded as a standard practice for actual applications. In the typical case of $\beta$-phase $\mathrm{Cu}-\mathrm{Al}-\mathrm{Ni}$ alloys, coarse grain size and large orientation dependence of elastic as well as martensitic strains ${ }^{1)}$ are reported to cause fracture along grain boundaries. Grain refinement discourages intergranular fractures significantly and extends fatigue life in $\mathrm{Cu}-\mathrm{Al}-\mathrm{Ni}^{2,3)}$ and $\mathrm{Cu}-\mathrm{Zn}-\mathrm{Al}^{4)}$ alloys. While some workers have applied powder metallurgical techniques ${ }^{5,6)}$ and ultrarapid quenching, ${ }^{7-9)}$ the majority practices microalloying with the fourth element ${ }^{2-4,10-14)}$ to obtain a fine grain size. Examples of refinement additives include $\mathrm{B},{ }^{10)} \mathrm{V},{ }^{4)}$ and $\mathrm{Zr}^{11}$ for $\mathrm{Cu}-\mathrm{Zn}-\mathrm{Al}$ alloys, and $\mathrm{Fe}^{12)} \mathrm{B},{ }^{13-15)} \mathrm{Ti},{ }^{16,17)}$ and $\mathrm{Cr}^{15)}$ for $\mathrm{Cu}-\mathrm{Al}-\mathrm{Ni}$ alloys. However, the role and functions of dopants on the grain refinement in shape memory alloys have not been studied in detail. The primary concern in this work is to know how and where dopant elements are distributed in an alloy and how they are related to the grain refinement effect in $\mathrm{Cu}-\mathrm{Al}-\mathrm{Ni}$ shape memory alloys.

Kamei and coworkers, ${ }^{16,17)}$ after examining various grain-refining additives to $\mathrm{Cu}-\mathrm{Al}-\mathrm{Ni}$ alloys, concluded that $\mathrm{Ti}$ refines grain size most effectively. In the Ti-doped alloys, a Ti-rich globular second phase (termed $X$ phase after Kamei ${ }^{16)}$ is introduced throughout the $\beta$ grain, which has been considered to play a significant role in grain refinement and mechanical improvement. According to them, the $X$ phase is introduced as a result of the following reactions ${ }^{16)}$;

Liquid $\rightarrow$ Primary $X$ phase freezing $\rightarrow$ Peritectic reaction $(L+X \rightarrow \beta) \rightarrow$ Consumption of $X$ into a single $\beta$ phase $\rightarrow X$ phase re-emergence by precipitation in the $\beta$ phase.

They suggest that the grain refinement originates from the increased nucleation rate of the $\beta$ phase by the formation of primary $X$ phase crystallites which act as effective nuclei through the peritectic reaction. On the other hand, Elst $e t$ al. ${ }^{14)}$ claim that the $X$ phase is formed during the last stage of solidification via a different peritectic reaction, $L+\alpha \rightarrow \beta+X$, where $\alpha$ denotes the $\mathrm{Cu}$-rich fec $\alpha$ solid solution in the $\mathrm{Cu}-\mathrm{Al}$ based system. However, both the above processes appear to be proposed with insufficient experimental basis and may require a reexamination.

It is also suggested that the $X$ phase particles suppress grain growth. ${ }^{14,16)}$ However, an observation that the $X$ phase is not particularly located at grain boundaries prompted Sure and Brown ${ }^{2)}$ and Lee and Wayman ${ }^{18)}$ to attribute the grain refinement effect to the small amount of $\mathrm{Ti}$ in solid solution. Recent transmission electron microscopic observations ${ }^{19,7}$ have revealed that there exist, in addition to the large metallography-scale $X$ phase inclusions (hereafter designated as $X_{L}$ ) as reported by the previous workers, two-orders-of-magnitude smaller $X$ phase inclusions (termed $X_{S}$ ) which are scattered evenly in the matrix at high density. The structures of $X_{L}$ and $X_{S}$ phases were both found to be the Heusler type $\left(L 2_{1}\right)$ with the composition close to $(\mathrm{Cu}, \mathrm{Ni})_{2} \mathrm{TiAl}^{19}{ }^{19}$ The $X_{L}$ phase holds a cube-to-cube parallel orientation relationship with the $\mathrm{DO}_{3}$ matrix phase with the lattice mismatch of $2.15 \%$. This work intends to clarify the formation process of these $X$ phases and to consider its relation to the grain refinement in Ti-doped 
$\mathrm{Cu}-\mathrm{Al}-\mathrm{Ni}$ alloys.

\section{Experimental}

Five alloys of composition $\mathrm{Cu}_{82-x} \mathrm{Al}_{13.8} \mathrm{Ni}_{4.2} \mathrm{Ti}_{x}$ $(0.01 \leqq x \leqq 0.60$, in mass \% $)$ have been melted in a vacuum induction furnace. The alloy with $0.38 \% \mathrm{Ti}$ contains less than $0.01 \% \mathrm{~B}$. The ingots were hot rolled at $1123 \mathrm{~K}$ into plates with $2 \mathrm{~mm}$ thickness, cut into pieces, and annealed at $1173 \mathrm{~K}$ for different durations. Grain size at each process was evaluated by the linear intercept method.

Two alloys of composition $\mathrm{Cu}_{81.0} \mathrm{Al}_{13.8} \mathrm{Ni}_{4.2} \mathrm{Ti}_{1.0}$, and $\mathrm{Cu}_{80.0} \mathrm{Al}_{13.8} \mathrm{Ni}_{4.2} \mathrm{Ti}_{2.0}$ have been melted in an arc furnace, homogenized in $\mathrm{N}_{2}$ atmosphere at $1273 \mathrm{~K}$ for $24 \mathrm{~h}$, cut into pieces, and then subjected to various final heat treatments at $1073 \sim 1323 \mathrm{~K}$ for various durations before quenching in iced water. These specimens were put forward to a microscopic investigation of the $X$ phases. An alloy $\mathrm{Cu}_{74.6} \mathrm{Al}_{12.7} \mathrm{Ni}_{3.9} \mathrm{Ti}_{8.9}$ was made by melting the $2 \% \mathrm{Ti}$ alloy and pure $\mathrm{Ti}$ in an evacuated quartz tube in an electric furnace, in order to confirm the hyper-eutectic microstructure.

In most cases observations have been made after applying the "betatization" treatment, i.e., $1173 \mathrm{~K} /$ 5 min holding followed by water quenching. Undoped $\mathrm{Cu}-\mathrm{Al}-\mathrm{Ni}$ alloys have a single $\beta$-phase region at temperatures between about 1000 and $1290 \mathrm{~K}$. Holding a sample at the $\beta$-phase temperature followed by quenching is conventionally called the betatization treatment and this terminology is preserved in this paper even though the Ti-doped $\mathrm{Cu}-\mathrm{Al}-\mathrm{Ni}$ may not completely be in a single phase of $\beta$ in the " $\beta$ phase temperatures". The betatization treatment is a prerequisite for obtaining the shape memory effect but is also required to re-solutionize the eutectoid $\gamma_{2}$ phase which is widely introduced in the $\beta$ phase at slower cooling rate and obscures grain boundaries and misleads an identification of the $X_{L}$ phase.

Microscopic observations and composition analysis were made using a Shimadzu EMX-SM7 electron probe microanalyzer (EPMA) and a Jeol JEM-2000EX transmission electron microscope (TEM) with an EDX analyzer. TEM foils were prepared by a Tenupol double-jet electropolishing unit with a solution of $33 \%$ nitric acid and methanol at $263 \mathrm{~K}$. Solidification behavior was monitored with a TGD5000 differential thermal analyzer (DTA) by scanning between room temperature and $1673 \mathrm{~K}$ at the rate of $2 \sim 10 \mathrm{~K} / \mathrm{s}$ in an $\mathrm{Ar}$ atmosphere.

\section{Results and Discussion}

\subsection{Grain Refinement Effect of $\mathrm{Ti}$}

Grain size was found to depend significantly on prior thermal and mechanical treatment and on the amount of Ti dopant. Fig. 1 shows the mean grain size measured at cast-hot-roll-annealing processes. Chemically analyzed $\mathrm{Ti}$ content is shown for each alloy. Two characteristics are immediately noticed; a notable reduction in grain size during hot working

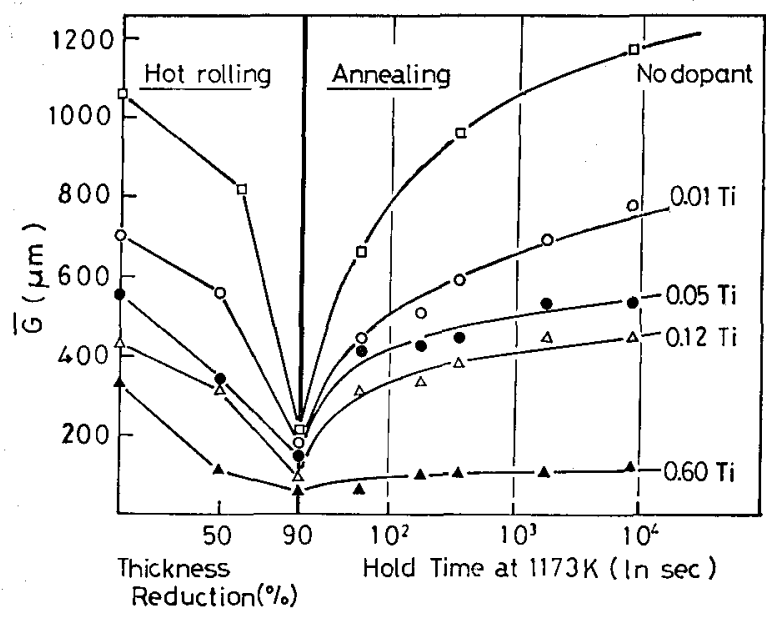

Fig. 1. Variation of average grain size with applied hot work at $1123 \mathrm{~K}$ and annealing time in the $\beta$-phase temperature.

and a subsequent coasening on annealing. One can find that the addition of $\mathrm{Ti}$ is very effective in reducing the as-cast grain size and suppressing the grain coarsening. However, the effect of $\mathrm{T} i$ is small for the grain refinement during the hot working. Columnar grain structure dominated in all the as-cast ingots but it completely changed into a homogeneous equiaxed one after $90 \%$ hot-rolling. The coarsening of these grains during subsequent annealing is almost completely prohibited if an alloy contains more than $0.6 \% \mathrm{Ti}$. The amount of grain-size reduction increases monotonically with increasing $\mathrm{Ti}$ content at least up to $0.6 \%$. Microscopic observations indicate that the $X_{L}$ phase is found when Ti content exceeds $0.38 \%$ while the $X_{S}$ phase is found when $\mathrm{Ti}$ content exceeds $0.05 \%$, as will be shown later.

\subsection{Distribution of $\mathrm{Ti}$ Atoms and Formation of the $X_{L}$ Phase}

Fig. 2 shows optical micrographs of alloys with $2 \% \mathrm{Ti}$ after the homogenization treatment and the final heating at various $\beta$-phase temperatures. The $X_{L}$ particles are distributed throughout the sample with only a minute tendency to coarsen as temperature and/or holding time are increased, Figs. 2(a) to 2(c), except when held at $1293 \mathrm{~K}$ at which partial melting takes place, Fig. 2(d). The size, hardness, and composition of the $X_{L}$ phase are essentially the same irrespective of the final treatment applicd as shown in Figs. 3 and 4, suggesting that it is already nearly equilibrated during prior homogenization in the $\beta$ phase temperature. At $1293 \mathrm{~K}$ (Fig. 2(d)), $X_{L}$ shows an Ostwald-type growth with a tendency to incorporate more $\mathrm{Ni}$ in place of $\mathrm{Cu}$, Fig. 4, and correspondingly the hardness increases as shown in Fig. 3. The $X_{S}$ phase was not identified by optical microscopy except when samples were heavily etched to develop etch pits of $X_{S}$. The compositions of $X_{L}$ and $X_{S}$ have been determined by using EPMA and TEM-EDX, respectively, and are numerically listed in Table 1. Both these second phases are ordered in the Heusler type $\left(L 2_{1}\right)$ structure in which $\mathrm{Ti}$ atoms occupies a 


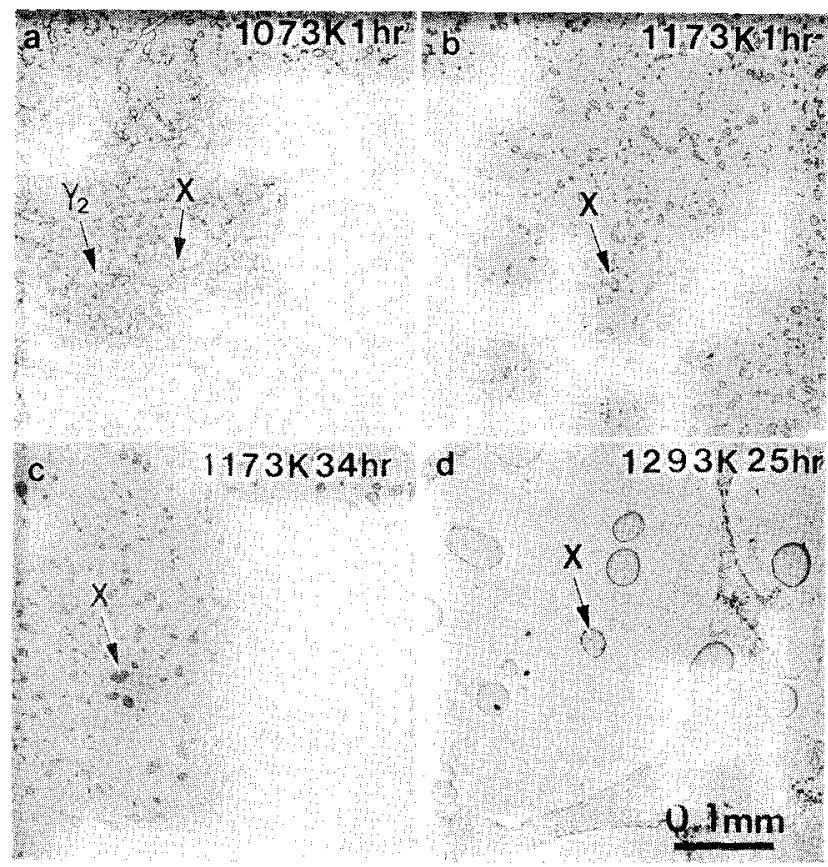

Fig. 2. Optical micrographs of $\mathrm{Cu}_{80.0} \mathrm{Al}_{13.8} \mathrm{Ni}_{4,2} \mathrm{Ti}_{2.0}$ alloy with a homogenization at $1273 \mathrm{~K}$ for $24 \mathrm{~h}$ and final treatments of (a) $1073 \mathrm{~K} / 1 \mathrm{~h}$, (b) $1173 \mathrm{~K} / 1 \mathrm{~h}$, (c) $1173 \mathrm{~K} / 34 \mathrm{~h}$, and (d) $1293 \mathrm{~K} / 25 \mathrm{~h}$.

Table 1. Compositions (in at\%) of $X_{L}$ and $\beta$ (including $X_{S}$ ) as determined by EPMA, and of $X_{S}$ as determined by TEM-EDX for a $2 \% \mathrm{Ti}$ alloy held at $1173 \mathrm{~K}$ for $1 \mathrm{~h}$ and quenched in water.

\begin{tabular}{lcrrc}
\hline & $\mathrm{Cu}$ & \multicolumn{1}{c}{$\mathrm{Ni}$} & \multicolumn{1}{c}{$\mathrm{Ti}$} & $\mathrm{Al}$ \\
\hline$X_{L}$ & 33.2 & 18.8 & 25.1 & 22.8 \\
$\beta$ & 70.9 & 2.7 & 0.2 & 26.2 \\
$X_{S}$ & 35.4 & 19.0 & 23.9 & 21.6 \\
\hline
\end{tabular}

quarter of sites. ${ }^{19)}$ The volume fraction of $X_{L}$ as measured by the point count method for the $2 \% \mathrm{Ti}$ alloy was $7.9 \%$.

The formation process of the $X$ phases has then been studied by applying different heat treatment. A sample quenched from liquid, Fig. 5(a), shows a dendritic primary $\beta$ phase (bright region) surrounded by a dark interdendritic region. The interdendritic region is found by EPMA to contain high concentration of $\mathrm{Ti}$ and $\mathrm{Ni}$ atoms. The transmission electron image, Fig. 6(a), elucidates that this is a mixture of the $X$ and $\beta$ phases, the latter transforming into $\gamma_{2}$ eutectoids and $\gamma_{1}^{\prime}$ martensites owing probably to compositional inhomogeneity. When the alloy with the above microstructure is annealed at $\beta$ temperature, it gradually equilibrates into one with uniformly distributed grown $X\left(X_{L}\right)$ phase, as shown in Figs. 5(b) and $5(\mathrm{c})$.

For a slowly-frozen sample, Fig. 5(d), the primary $\beta$ grows much larger and $X_{L}$ is grown visible with a dot-like contrast. The arrays of $X_{I}$, particles exist only at prior interdendritic regions and the $\beta$ grains are shown in the polarized micrograph to grow beyond them. In either melt-quenched or slowly-frozen

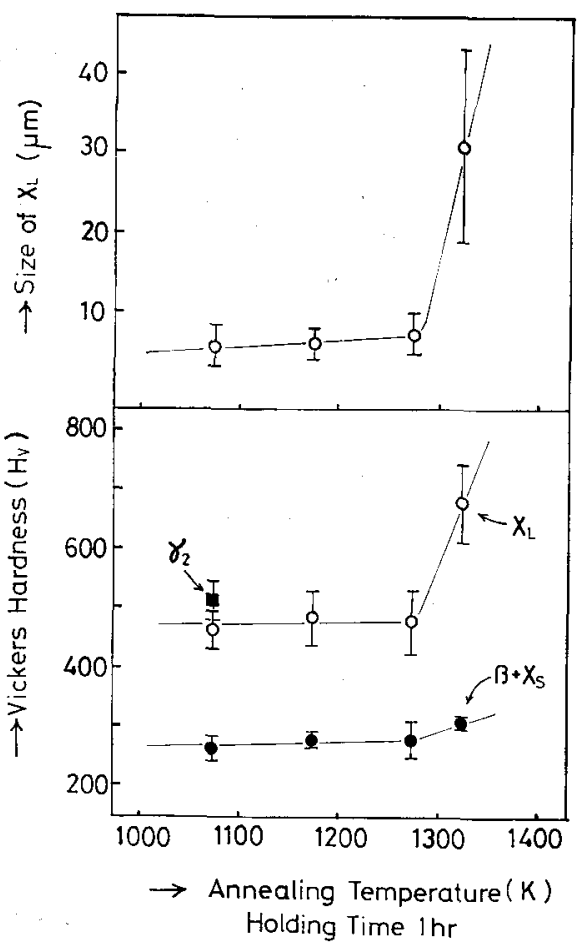

Fig. 3. Diameter and Vickers hardness of the $X_{L}$ phase together with the hardness of $\gamma_{2}$ and the $\beta+X_{S}$ matrix in an alloy with $2 \% \mathrm{Ti}$ measured after 1-h isochronal annealing at $\beta$-phase temperatures.

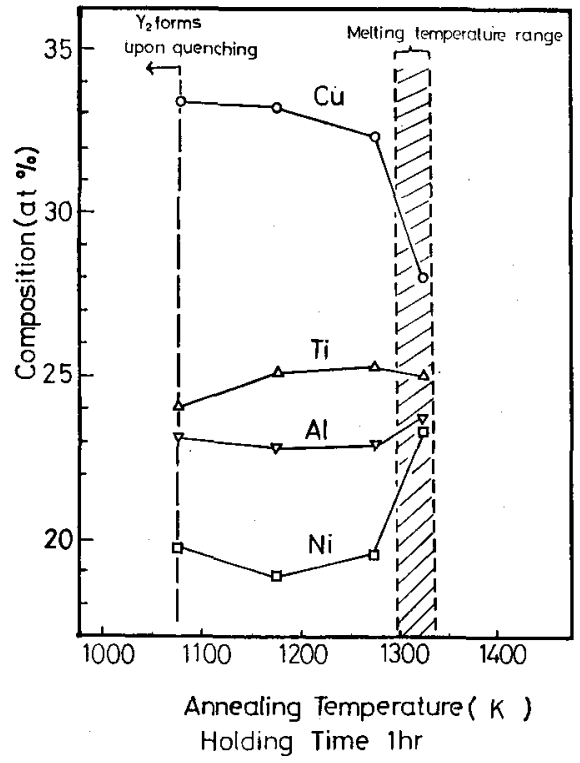

Fig. 4. Composition of the $X_{L}$ phase as determined by EPMA for a $2 \%$ Ti alloy measured after 1 -h isochronal annealing at $\beta$-phase temperatures.

specimens we could not observe any peritectic nuclei, such as the $X$ phase $^{16)}$ or the $\alpha$ phase, ${ }^{14)}$ which might have retained in the $\beta$ phase if the peritectic reactions have taken place. Nor could we obtain, by quenching a sample from any temperature, the $X$-phase-free $\beta$ single phase which has been assumed by Kamei et al. ${ }^{16)}$ Dot-like or large particulate $X$ phases are often present inside the primary $\beta$ phase but they are mostly present in group and are not considered to be 
(a), (e): As-quenched from liquid (b), (c): Quenched from liquid and annealed at $1223 \mathrm{~K}$ (d), (f): As-frozen at $2 \mathrm{~K} / \mathrm{min}$ Fig. 5.

Optical micrographs of alloys containing (a) to (d) $2 \% \mathrm{Ti}$, (e) $1 \%$ $\mathrm{Ti}$, and (f) $8.9 \% \mathrm{Ti}$.
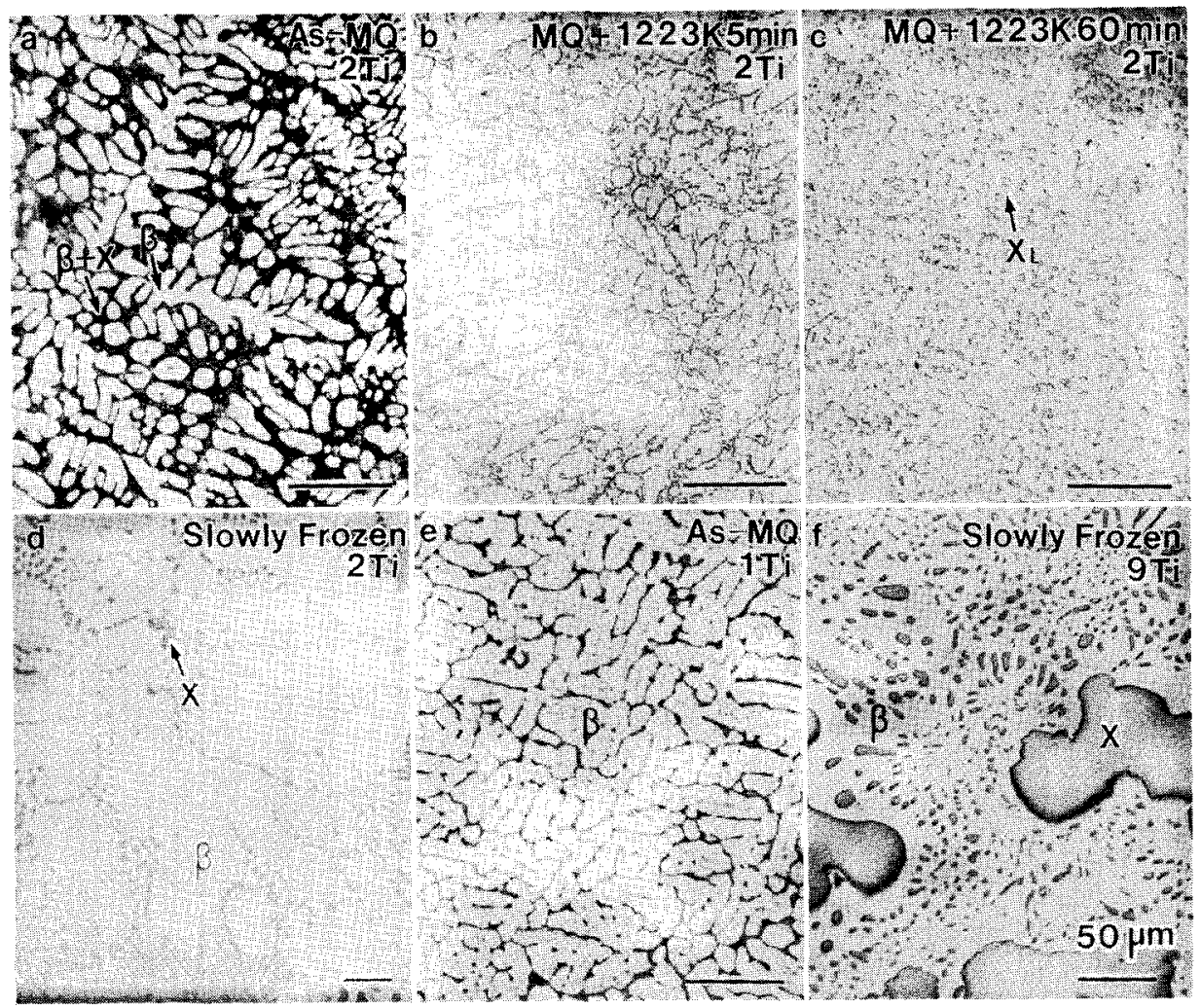

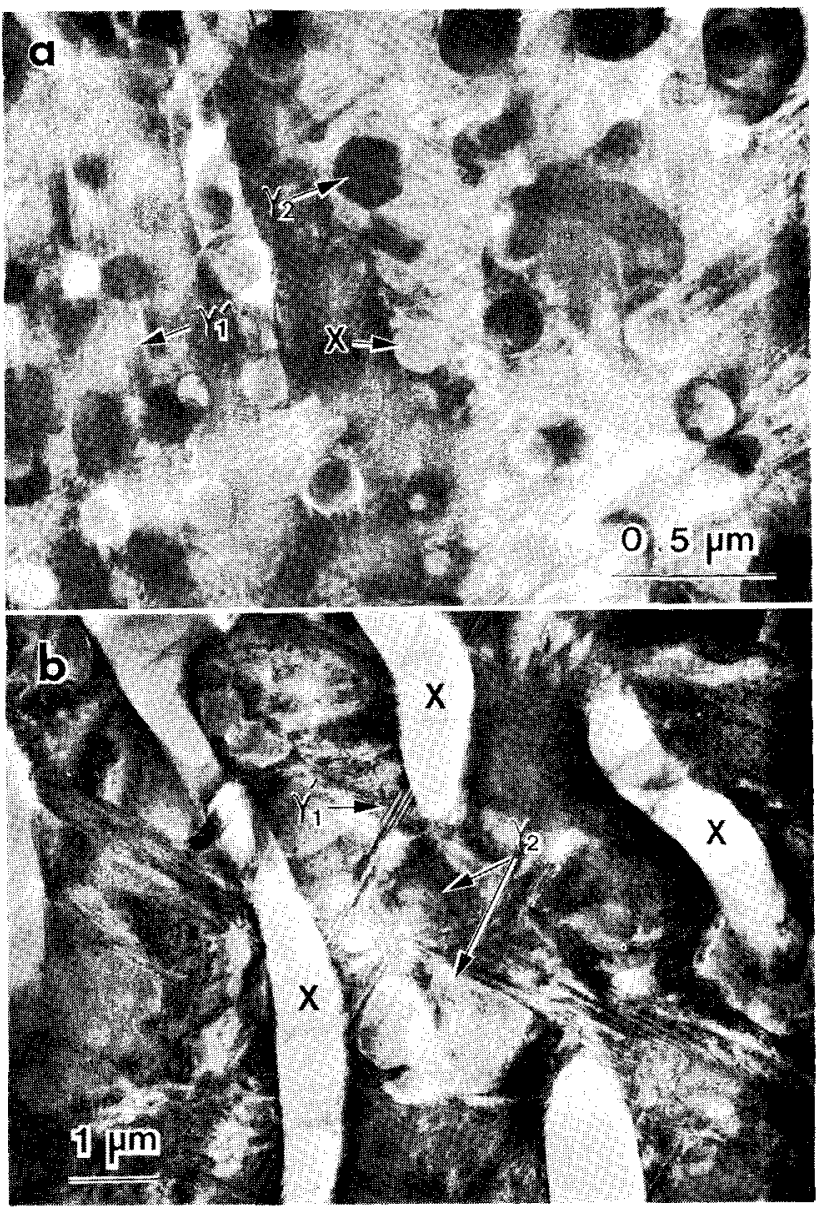

Fig. 6. TEM images of interdendritic region in $2 \% \mathrm{Ti}$ specimens as-quenched from liquid (a) and from partial-melting temperature (b), respectively. the peritectic nuclei.

On the other hand, it is evident that the present alloy system involves a eutectic reaction forming an aggregate of $X$ phase and $\beta$ phase, where at $2 \% \mathrm{Ti}$ composition an alloy constitutes a hypoeutectic composition. An alloy with $1 \%$ Ti shows a similar structure when quenched from liquid, Fig. 5(e), with the primary $\beta$ dendrites dominating the volume. At $8.9 \% \mathrm{Ti}$, the slowly-frozen microstructure, Fig. 5(f), clearly shows the presence of blocky primary $X$ phase, indicating a hypereutectic composition. The morphology of the equilibrated $X_{L}$ phase depends on the initial $X$ phase in the $\beta / X$ aggregate: as the cutectic freezing rate decreases, the equilibrated $X_{L}$ phase becomes more elongated or rod-like as shown in Fig. 6(b). The equilibrium shape of $X_{I}$ after sufficient annealing at high temperatures appears to be a spheroid.

In order to monitor the melting/freezing behavior, DTA measurements have been employed. As shown in Fig. 7(a), no extra peaks were observed between $1673 \mathrm{~K}$ and freezing/melting temperatures. The freezing peak shows a clear split at the slower scan rate of $2 \mathrm{~K} / \mathrm{s}$, Fig. 7 (b), where the first smaller peak and the second larger peak are considered to correspond to the primary $\beta$ freezing and the $\beta+X$ eutectic freezing, respectively. The peak magnitudes are apparently inconsistent with the volume fractions of the primary $\beta$ and the eutectic, but this presumably owes to the difference in the latent heat of freezing. A comparison of the profiles for 2 and $8.9 \% \mathrm{Ti}$ implies that the heat of freezing for the $X$ phase is much larger than that for the primary $\beta$.

Fig. 8 presents anti-phase domain boundaries (APB) of an alloy containing $2 \% \mathrm{Ti}$ as imaged using 


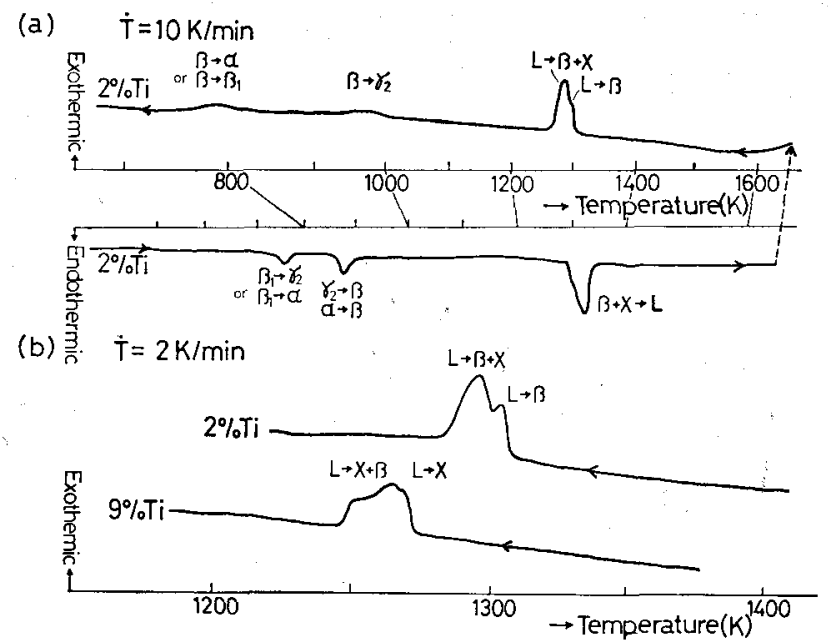

Fig. 7. Plot of DTA thermograms of alloys containing $2 \% \mathrm{Ti}$ and $8.9 \% \mathrm{Ti}$, showing melting and freezing peaks at different heating/cooling rate. Actual cooling rate in (a) is partially lower than $10 \mathrm{deg} /$ min, resulting in a different scale in abscissa.

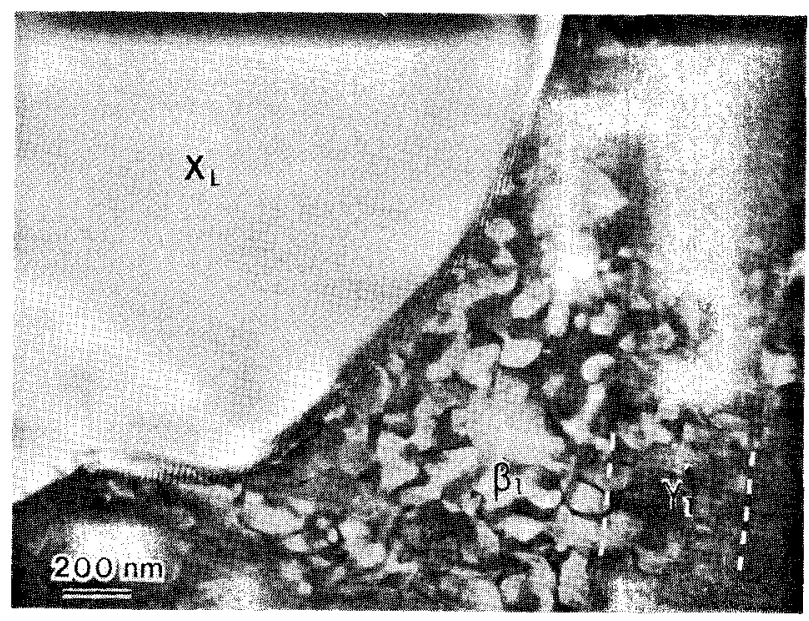

Fig. 8. Dark field image using $L 2_{1}$ superlattice reflection in a $2 \% \mathrm{Ti}$ alloy showing $\mathrm{APB}$ network in the matrix but no APB contrast inside $X_{L}$.

$L 2_{1}$ superlattice reflection. Continuous succession of APB across the $\beta_{1}$ matrix and the $\gamma_{1}^{\prime}$ martensite plate of course reflects the order of transformation events on cooling; $\beta \rightarrow \beta_{1}$ (ordering reaction) $\rightarrow \gamma_{1}^{\prime}$ (martensitic transformation). No APB whatsoever has been ob= served in the $X_{L}$ phase, suggesting that the ordering in the $X_{L}$ does not occur from disordered solid state, but occurs rather concurrently with the freezing of the $X$ eutectic. This is a reflection of the high ordering energy of $(\mathrm{Cu}, \mathrm{Ni})_{2}$ AlTi phase as in the case of other Berthollide type intermetallic compounds such as $\mathrm{Ni}_{2} \mathrm{AlTi}$ and NiAl. That the $X_{L}$ phase has a fairly defect-free structure has also been confirmed by lattice imaging which showed no disturbance of (111) lattice planes inside $X_{L}$. However, a small amount of an extraneous phase was observed inside $X_{L}$ on quenching from the lower $\beta$ temperature, e.g., $1073 \mathrm{~K}$. It is apparently a precipitation product of intermetallic compound such as $\mathrm{NiAl}, \mathrm{NiAl}_{3}, \mathrm{NiTi}$, etc., but was not identified.

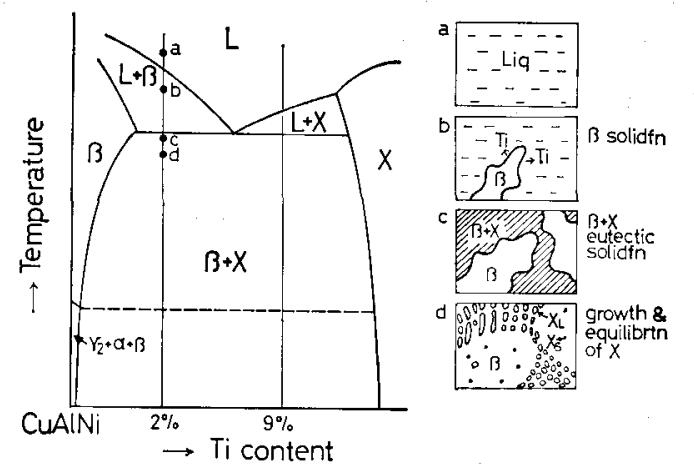

Fig. 9. Schematic pseudo-binary phase diagram for CuAl$\mathrm{Ni}-\mathrm{Ti}$ and schematic figures showing the formation process of the $X$ phases.

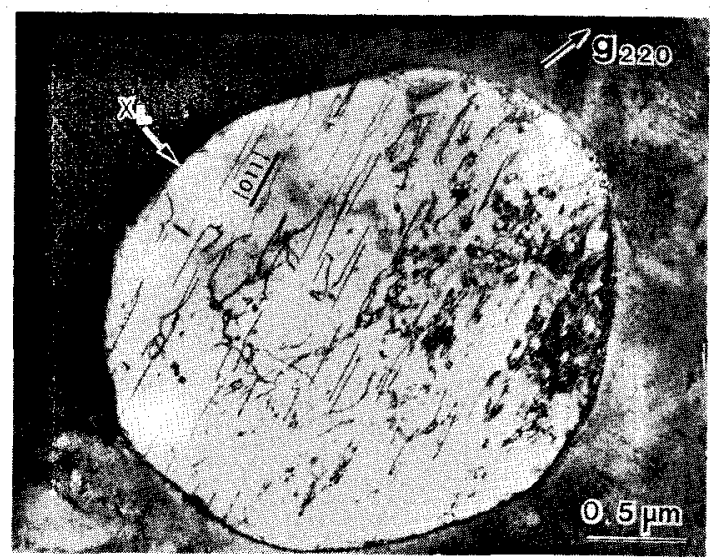

Fig. 10. Bright field TEM image of $X_{L}$ in heavily cold rolled $2 \% \mathrm{Ti}$ alloy.

The formation process of the $X_{t}$. phase may be summarized in the schematic pseudo-binary phase diagram of Fig. 9. In the normal as-melted or ascast condition, fine $\beta / X$ eutectic aggregates are formed which is not in its equilibrium state but can be progressively equilibrated during homogenization treatment to result in a microstructure with uniformly distributed $X_{L}$ phase. The final shape of the $X_{L}$ phase is usually spheroidal but may be rod-like when the freezing rate is low. On the other hand, the current observations have provided no evidence for the existence of either the primary $X$ or $\alpha$ phase crystallites or the peritectic reactions as proposed by Kamei et al. ${ }^{16)}$ and Elst et al. ${ }^{14)}$

The hardness of $X_{I}$ was shown in Fig. 3 to be about $470 \mathrm{VHN}$, which is much harder than the matrix $\beta_{1}$ and is not very different from that of $\gamma_{2}$ eutectoid, $510 \mathrm{VHN}$. TEM image of cold-rolled sample is shown in Fig. 10. Matrix $\beta_{1}$ phase completely transforms to martensite, while $X_{L}$ does not undergo martensitic transformation but deforms by introducing dislocations which are trace-analyzed to lie on $\{101\}$ and be stretched in $\langle 111\rangle$.

The Heusler-type structure of $X_{L}$ and $X_{S}$ is generally known to be quite brittle at room temperature. But $\mathrm{Ni}_{2} \mathrm{AlTi}$ alloys ${ }^{20)}$ which have a similar composition to the $X_{L}$ and $X_{S}$ phases, show substantial plasticity at above $965 \mathrm{~K}$ by activating $\langle 101\rangle$ slips on both $\{101\}$ and $\{100\}$ planes. Thus, $X_{L}$ and $X_{S}$ can 
also be expected to show some ductility at most $\beta$ phase temperatures. This is in agreement with the easiness of hot working of the present alloys at $\beta$-phase temperatures.

\subsection{Behavior of $X_{S}$ during $\beta$-temperature Annealing}

Contrary to the $X_{L}$ phase, the $X_{S}$ particles show a distinct morphological change during high temperature treatment. In an as-homogenized sample $X_{S}$ initially holds a cuboidal shape (Fig. 11(a)), but a careful inspection indicates that the cube planes are deviated slightly from $\{100\}$ of the $\beta$ phase depending on particles. When given more extensive treatment, the deviation becomes more pronounced as $X_{S}$ grows and evolves into one with protrusions as shown in Figs. 11 (b) and 11 (c), and then apparently splits, Fig. 11(d). Crystallographic direction of these protrusions has been determined to be $\langle 111\rangle$ by trace analysis. Examples of the observations from $\langle 100\rangle,\langle 111\rangle$ and $\langle 011\rangle$ directions are shown in Fig. 12, where $X_{S}$ was assumed to hold a cube-to-cube parallel orientation relationship with matrix $\beta$ as is the case with $X_{L} \cdot{ }^{19)}$ The ultimate morphology upon annealing is considered to be a cluster of eight ellipsoids split in eight $\pm\langle 111\rangle$ directions. This type of behavior of precipitate growing to split into subparticles is analogous to those seen in the $\gamma^{\prime}$ precipitates in Ni-base alloys, ${ }^{21)}$ which decompose from an initial cube into doublets of rectangular plates or octets (ogdoads) of subcubes depending on heat treatment and alloy composition. Miyazaki et al. ${ }^{22)}$ have analyzed this behavior from the viewpoint of the interaction of elastic strain energy between precipitates, which were approximated as spheroids. Khachaturyan et al. ${ }^{23)}$ have undertaken more rigorous calculation based on the cube morphology and could justify the analysis with excellent agreement with experimental data. The present splitting behavior of the $X_{S}$ particles may derive from the same origin, considering the similarity of composition as well as the high elastic anisotropy of the $\beta$ phase $\left(A=2 C_{44} /\left(C_{11}-C_{12}\right)=11.924\right)$.

In addition to the growth of $X_{S}$, a planar precipitation on $\{100\}$ of the $\beta$ phase occurs as seen in Figs. $11(\mathrm{~b})$ and $11(\mathrm{c})$. Although these precipitates were not identified, it was observed that they do not interrupt the growth of martensite plate and hence the shape memory effect.

Since the size of $X_{S}$ increases at each interval of $\beta$ temperature holding and quenching, the $X_{S}$ is concluded not to be a phase formed upon quenching due to less Ti solubility at room temperature as assumed before. ${ }^{19)}$ Rather, it is a precipitation product in the $\beta$ phase. The eutectic $\beta$ would probably provide the supersaturated $\mathrm{Ti}$ atoms. The primary $\beta$ dendrite in specimens as quenched from liquid rarely contained $X_{S}$ but upon annealing at $1173 \mathrm{~K}$ for $1 \mathrm{~h}, X_{S}$ of $30 \sim$ $50 \mathrm{~nm}$ was produced evenly in the $\beta$ phase at similar density as in samples which were normally cast and homogenized. The $\beta$ phase in slowly-frozen specimens contained appreciably smaller number of, but larger-sized $(80 \sim 100 \mathrm{~nm}) X_{S}$, indicating that it was

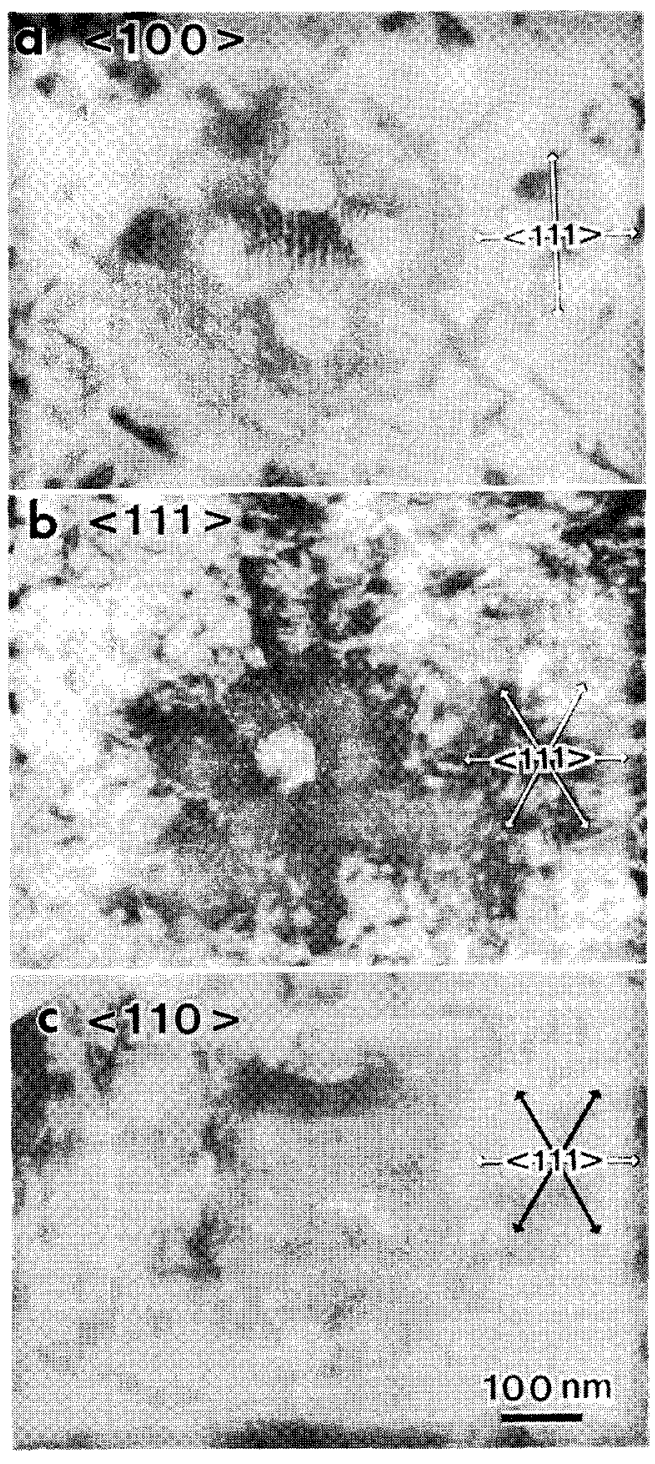

Fig. 12.

TEM micrographs of $X_{S}$ viewed from (a) $\langle 100\rangle$, (b) $\langle 111\rangle$, and (c) $\langle 110\rangle$ directions in a $2 \% \mathrm{Ti}$ alloy heated at $1173 \mathrm{~K}$ for $34 \mathrm{~h}$.
Fig. 11. TEM micrographs of the $X_{S}$ phase in a $2 \%$ Ti alloy after applying various annealings in the $\beta$-phase temperatures. 
not formed upon quenching but formed in the $\beta$ temperature. $X_{S}$ was also observed in the $\gamma_{2}$ eutectoid.

The volume fraction of $X_{S}$ in the $2 \% \mathrm{Ti}$ alloy after the $1173 \mathrm{~K} / 1 \mathrm{~h}$ heating was measured from TEM micrographs to give $0.9 \%$. Although this number is not very precise, it is reasonable when considering the EPMA-determined composition of the $\beta$ phase containing $X_{S}$, which gave $0.2 \%$ Ti. Combining these with the compositions of the $X_{L}$ and $X_{S}$ phases as given in Table $\mathrm{I}$, the fraction of $\mathrm{Ti}$ in $X_{L}$ and $X_{S}$ together amounts to $2.1 \%$, indicating that almost all the Ti atoms doped are forming $X_{L}$ or $X_{S}$ and the solid solubility of $\mathrm{T} i$ in the $\beta$ phase is close to nil. Transmission electron micrographs of alloys with various Ti contents are shown in Fig. 13, where the presence of $X_{S}$ is evident for the $0.12,0.38$ and $0.60 \% \mathrm{Ti}$ alloys. For the 0.01 and $0.05 \% \mathrm{Ti}$ alloys, $X_{S}$ does not appear to exist in the $\beta$ phase as shown in Figs. 13(a) and 13(c). However, there are some implications that $\mathrm{Ti}$ atoms might exist in very small clusters or precipitates. For example, many dot-like contrasts in the martensitic $0.01 \% \mathrm{Ti}$ alloy, Fig. 13(b), are not commonly observed in undoped $\mathrm{Cu}-$ $\mathrm{Al}-\mathrm{Ni}$ alloys. The density of short and curly dislocations in Figs. 13(a) and 13(c) is somewhat higher than for undoped alloys, and these dislocations might accompany small precipitates. In the $0.05 \% \mathrm{Ti}$ alloy some $X_{S}$ precipitates are actually found at grain boundaries as shown in Fig. 13(d). Therefore, it is supposed that $\mathrm{Ti}$ atoms tend to cluster or precipitate first at dislocations and grain boundaries and then in the matrix as the $\mathrm{Ti}$ content increases. The size of precipitates increases with increasing $T i$ content. The solid solubility of $\mathrm{Ti}$ is determined to be less than $0.05 \%$ but can be below $0.01 \%$ if Ti precipitates at dislocations.
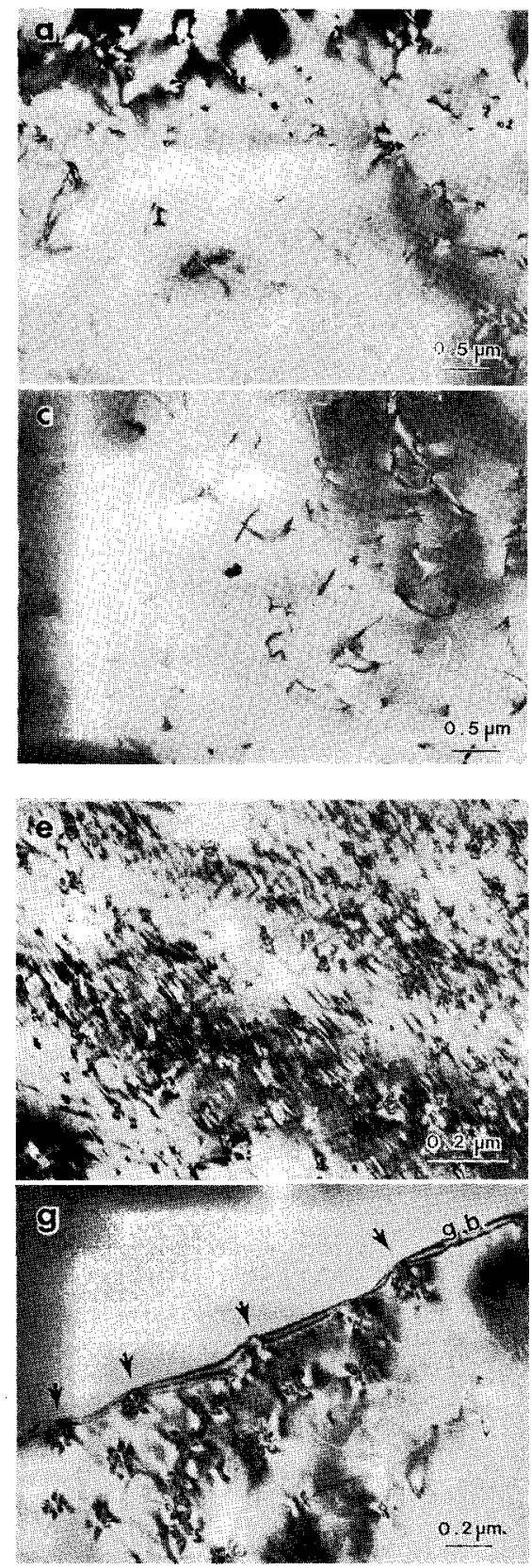
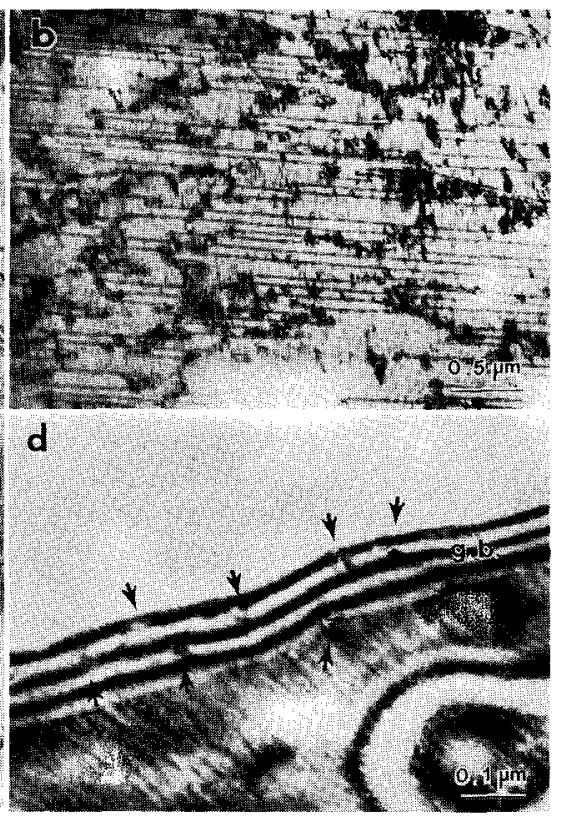

Fig. 13.

TEM micrographs of (a), (b) $0.01 \% \mathrm{Ti}$, (c), (d) $0.05 \% \mathrm{Ti}$, (e), (f) $0.12 \% \mathrm{Ti}$, (g) $0.38 \% \mathrm{Ti}$ and $(\mathrm{h}) 0.60 \% \mathrm{Ti}$ alloys held at $1173 \mathrm{~K}$ for $5 \mathrm{~h}$ except (b) which is as hot-rolled. 


\subsection{Origin of Grain Refinement in $\mathrm{Ti}$-doped $\mathrm{Cu}-\mathrm{Al}-\mathrm{Ni}$ Alloys}

In $\mathrm{Cu}$-based shape memory alloys the grain refinement is a result of the following three effects working cooperatively.

1) Grain refinement upon freezing

2) Grain refinement during hot working

3) Suppression of grain coarsening during homogenization, hot working, and betatization heating.

As shown in Sec. 3.1, the addition of Ti was found to be quite effective on 1) and 3) but not as much on 2). The effect 3) is important in Cu-based shape memory alloys since the bcc $\beta$ phase shows a tendency to coarsen prominently at high temperatures.

\subsubsection{Grain Refinement upon Freezing}

Grain refinement upon freezing is effected principally by either enhancing the nucleation rate $(\mathcal{N})$ or decreasing the growth rate $(G)$. In terms of the $\mathcal{N}$ enhancement, the existence of the peritectic reactions, $L+X \rightarrow \beta$ or $L+\alpha \rightarrow \beta+X$, is found to be doubtful as shown in Sec. 3.2. Although the $X_{L}$ phase grows large at $L+\beta$ temperatures, it was confirmed to dissolve above the matrix melting temperature. Then, other realistic candidates for a possible nucleation center in the melt would be either a stable carbide, TiC, or some Ti-rich intermetallic compound. In dilute $\mathrm{Al}$ alloys, a dramatic grain refinement can be accomplished by doping $\mathrm{Ti}$, where $\mathrm{Ti}$ apts to combine with trace impurity $\mathrm{C}$ to form $\mathrm{TiC}$ nucleant in the melt. ${ }^{25,26)}$ Also, a well-known peritectic theory ${ }^{27)}$ attributes to $\mathrm{Al}_{3}$ Ti and other $\mathrm{Al}_{x}$ Ti nucleation agents. ${ }^{26}$ ) Thus, a thorough EPMA search for possible TiC and/ or $\mathrm{Al}_{x}$ Ti nucleants in the $\beta$ dendrite of the meltquenched sample has been made, but no positive results have been obtained. DTA measurement detected no extra peaks above the melting temperature up to $1623 \mathrm{~K}$. These results provide no evidence for the existence of effective nucleant.

In the other aspect, the addition of less than $0.2 \%$ of grain refiners can cause a decisive effect ranging from a hundred to thousand-fold reduction in the case of $\mathrm{Al}$ and $\mathrm{Mg}$ alloys. However, the present reduction hardly exceeds ten-fold which is normally found in the $G$-suppression type refinement. ${ }^{28)}$ The as-cast structure of the present alloys changed from coarse columnar to fine columnar to fine equiaxial with increasing $\mathrm{Ti}$ content, and $1 \sim 2 \% \mathrm{Ti}$ addition was necessary to obtain equiaxed grains. Considering the above situations, we presume that there exist no effective nucleant crystallites in the present alloy system and the grain refinement on freezing is caused solely by the $G$-suppression effect.

The growth rate of a phase involving phase separation is generally retarded by the solute build-up ahead of the transformation front, known as the constitutional supercooling effect. ${ }^{29)}$ The growth velocity $G$ of primary $\beta$ dendrite in a binary alloy is generally expressed as $^{30}$

$$
G=\left(D_{L} \cdot \nabla C\right) /\left(C_{L}-C_{S}\right)
$$

where, $D_{L}$ : the diffusion coefficient of solute in

\section{liquid}

$\nabla C$ : the composition gradient of solute in liquid at solidification front

$C_{L}, C_{S}:$ compositions of solute in liquid and $\beta$ phase, respectively.

Titanium atoms have strong attraction to $\mathrm{Ni}$ and $\mathrm{Al}$ atoms as may be expected from the existence of highmelting-temperature intermetallic compounds such as $\mathrm{TiNi}, \mathrm{TiAl}_{3}, \mathrm{TiAl}, \mathrm{Ni}_{2} \mathrm{TiAl}$, etc. The attractive force between $\mathrm{Ti}$ and other atom species may well decrease $D_{L}$ and thus $G$ will be substantially decreased. The extent of constitutional supercooling in the present quaternary system is hard to evaluate but we speculate that the decrease in $D_{L}$ is significant in decreasing the growth rate of the primary $\beta$ dendrites.

\subsubsection{Grain Refinement during Hot Working}

Hot working gives significant reduction in grain size through heavy deformation and simultaneous or subsequent recrystallization. However, the effect of $\mathrm{Ti}$ in this process was found to be small as shown in Fig. 1. The effect of $\mathrm{Ti}$ is probably that to restrain grain growth during hot working.

\subsubsection{Suppression of Grain Coarsening}

This effect contributes to grain refinement during homogenization, hot working and betatization treatment, i.e., in every process done in the $\beta$-phase temperature range. The lowered diffusion rate of constituent atoms by the existence of $\mathrm{Ti}$ in solid solution may be considered as the major factor to restrict the grain coarsening. ${ }^{2,18}$ In this case, the suppression effect would saturate when the dopant amount reaches solid solubility, estimated as $0.01 \%$ by Sure and Brown. ${ }^{2)}$ Our work has shown that the suppression effect increases monotonously with increasing amount of $\mathrm{Ti}$ at least up to $0.60 \%$, while the solid solubility at room temperature is less than $0.05 \%$. The solid solubility does not differ much at ambient and $\beta$-phase temperatures since we do not observe any significant amount of $X_{S}$ phase produced upon quenching due to the difference in solid solubility. Therefore, the effect of $\mathrm{Ti}$ in solid solution alone, if any, can not explain a large difference between the 0.05 and $0.60 \% \mathrm{Ti}$ alloys. Moreover, the diffusion event at $\beta$ temperatures is not quite low as suggested from Figs. 5(a) to 5 (c) which show the high rate of $X_{L}$ redistribution.

More dominating effect to restrict grain coarsening may be provided by the homogeneously dispersed second phases. As already shown in Figs. 13(d), 13(f) and $13(\mathrm{~g})$, the $X_{S}$ phase can be a significant pinning center for grain growth. The effect will increase with increasing number of $X_{S}$ and thus with increasing amount of $\mathrm{Ti}$. At $2 \% \mathrm{Ti}$, grain boundary is nearly pinned down by highly populated $X_{S}$ as shown in Fig. 14(a), although at this stage when $X_{S}$ is small and cuboidal in shape the stacking faults on martensite basal plane were observed to easily penetrate $X_{S}$. The protruded incoherent $X_{S}$ grown on extended annealing appears to have larger pinning effect as it is shown to pin even martensite plate boundaries, Fig. 14(b).

Of the $X_{L}$ and $X_{S}$ phases, the latter can afford at 


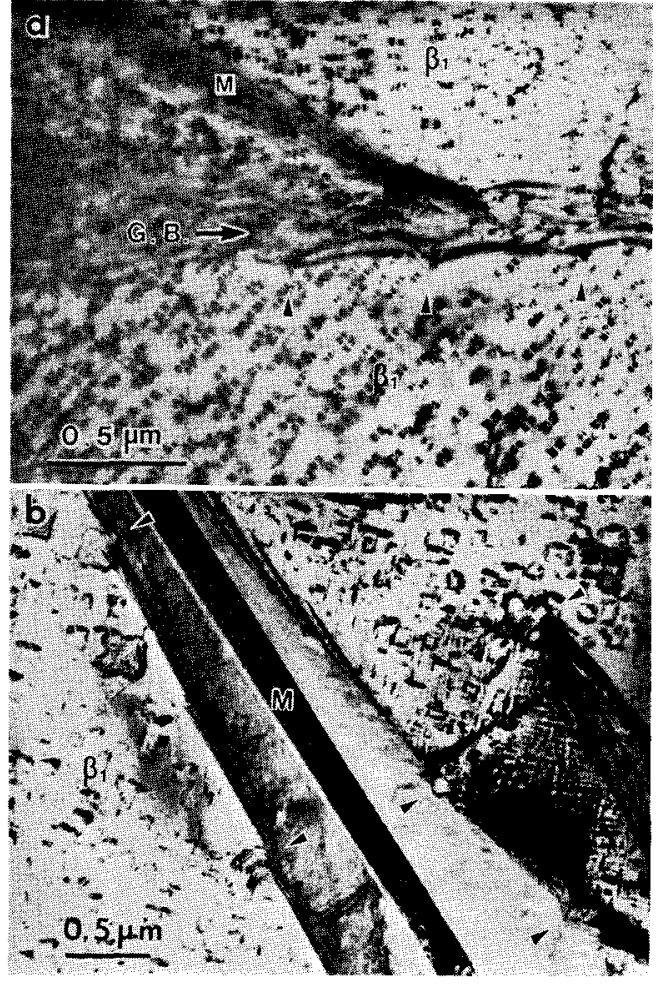

Fig. 14. TEM micrographs showing a pinning effect of $X_{S}$ in $2 \% \mathrm{Ti}$ alloys heated at $1173 \mathrm{~K}$ for (a) $1 \mathrm{~h}$ and (b) $34 \mathrm{~h}$.

least an order of magnitude greater pinning effect as follows. To a first approximation the pinning force per unit area of boundary, $F$, is proportional to $f / r$, where $f$ is the volume fraction and $r$ is the mean particle radius. ${ }^{311}$ Thus, at $2 \%$ Ti additions,

$$
\begin{aligned}
F\left(X_{S}\right) / F\left(X_{L}\right) & =\left(f\left(X_{S}\right) / f\left(X_{L}\right)\right) /\left(r\left(X_{S}\right) / r\left(X_{L}\right)\right) \\
& =(0.9 / 7.9) /(0.04 / 4.8)=13.7 .
\end{aligned}
$$

The grain refinement of $\mathrm{Cu}$-based shape memory alloys doped with other transition elements may in general be caused by the similar process as presented above. Actually the presence of small second phase corresponding to $X_{S}$ is reported for $\mathrm{V}$-doped $\mathrm{Cu}-\mathrm{Zn}$ $\mathrm{Al},{ }^{4)}$ and $\mathrm{Zr},{ }^{7)} \mathrm{Cr},{ }^{7)} \mathrm{B},{ }^{7)}$ or $\mathrm{Fe}^{32)}$-doped $\mathrm{Cu}-\mathrm{Al}-\mathrm{Ni}$ alloys.

\section{Conclusions}

Microscopic and microanalytical studies have been made to clarify the formation process of the $X$ phases and the grain refinement mechanism of Ti-doped $\mathrm{Cu}-$ Al-Ni shape memory alloys. The following results were obtained.

(1) Grain size is remarkably reduced during hot working, but the effect of Ti is small. Titanium addition is highly effective in decreasing as-cast grain size and in suppressing grain coarsening at high temperatures.

(2) The $\mathrm{Cu}-\mathrm{Al}-\mathrm{Ni}-\mathrm{Ti}$ forms a eutectic system with respect to the dopant Ti. For an alloy with less than 2 mass $\% \mathrm{Ti}$, the following sequence is followed on decreasing temperature from the melt:

Primary $\beta$ freezing $\rightarrow$ Eutectic freezing $(L \rightarrow \beta+$
$X) \rightarrow$ Growth and equilibration of $X$ to become $X_{L}$, and precipitation of $X_{S}$, during holding in the $\beta$-phase temperature.

(3) No evidence of the peritectic reactions, $L+$ $X \rightarrow \beta^{(6)}$ and $L+\alpha \rightarrow \beta+X,{ }^{14)}$ has been obtained.

(4) Solid solubility of $\mathrm{Ti}$ at room temperature is less than 0.05 mass $\%$ according to TEM observations.

(5) High temperature annealing gives only a small change in the size and distribution of the $X_{L}$ phase, but it enlarges and changes the morphology of the $X_{S}$ phase from cuboidal to $\langle 111\rangle$-protruded to eight split spheroids. Such changes presumably arise from the reduction in the elastic strain energy of the $X_{S}$ precipitates. Minor unidentified precipitations occur on $\{100\}$ of $\beta$ matrix and inside $X_{L}$ but they do not disturb the martensitic transformation.

(6) Grain refinement is considered to be a combined result of lowered growth rate of primary $\beta$ upon freezing and the pinning suppression of grain coarsening during hot working, homogenization and/or betatization treatment. The significant contributions for the former and the latter effects are provided by the lowered diffusion rate of constituent atoms due to the presence of $\mathrm{Ti}$, and the dense dispersion of the $X_{S}$ phase, respectively.

(7) $X_{L}$ deforms by slip on $\{101\}$ and is not particularly ductile or "soft" with VHN around 470, except at most $\beta$-phase temperatures where some ductilities are expected in analogy of $\mathrm{Ni}_{2} \mathrm{AlTi}$ Heusler alloys.

\section{REFERENCES}

1) S. Miyazaki, T. Kawai and K. Otsuka: Scr. metall., 16 (1982), 431.

2) G. N. Sure and L. C. Brown: Metall. Trans. A, 15A (1984), 1613.

3) G. N. Sure and L. C. Brown: Scr. metall., 19 (1985), 401.

4) K. Enami, N. Takimoto and S. Nenno: J. Phys. Colloq., 43 (1982), C4-773.

5) T. W. Duerig, J. Albrecht and G. H. Gessinger: J. Met., 34 (1982), Dec., 14.

6) J. Janssen, F. Willems, B. Verelst, J. Maertens and L. Delaey: J. Phys. Colloq., 43 (1982), C4-809.

7) S. Matsuoka, R. Oshima and E. Fujita: J.Jpn. Inst. Met., 48 (1984), 871.

8) J. Perkins, J. J. Rayment, B. Cantor and R. W. Cahn: Scr. metall., 15 (1981), 771.

9) W. M. Stobbs and J. V. Wood: Acta metall., 27 (1979), 575.

10) Y. Hanatate, M. Miyagi, T. Hanada and F. Uratani: Rep. Osaka Indust. Tech. Res. Inst., (1982), No. 81, 17.

11) J.S. Lee and G. M. Wayman: Proc. Int. Conf. on Martens. Transf. (ICOMAT-86, Nara), Japan Inst. Met., Sendai, (1987), 920.

12) A. H. Kasberg and D. J. Mack: Trans. AIME, 191 (1951), 903.

13) J. P. Dennison and E. V. Tull: J. Inst. Met., 81 (195253), 513.

14) R. Elst, J. Van Humbeeck, M. Meeus and L. Delaey: $Z$. Metallkd., 77 (1986), 421.

15) M. Miki, Y. Ogino and Y. Hiramatsu: J. Jpn Inst. Met., 51 (1987), 815.

16) K. Kamei, H. Matsumoto, K. Sugimoto, T. Sugimoto and 
T. Irizawa: J. Jpn Copper Res. Assoc., 19 (1981), 201.

17) K. Sugimoto, K. Kamei, H. Matsumoto, S. Komatsu and T. Sugimoto: J. Phys. Colloq., 43 (1982), C4-761.

18) J. S. Lee and C. M. Wayman: Trans. Jpn Inst. Met., 27 (1986), 584.

19) K. Adachi, Y. Hamada and Y. Tagawa: Scr. metall, 21 (1987), 453.

20) M. Yamaguchi, Y. Umakoshi and T. Yamane: Phil. Mag., 50 (1984), 205.

21) M. Doi, T. Miyazaki and T. Wakatsuki: Mater. Sci.Eng., 67 (1984), 247.

22) T. Miyazaki, K. Nakamura and H. Mori: J. Meter. Sci., 14 (1979), 1827.

23) A. G. Khachaturyan, S. V. Semenovskaya and J. W. Morris, Jr.: Acta metall., 36 (1988), 1563.

24) M. Suezawa and K. Sumino: Scr. metall., 10 (1976), 789.
25) A. Cibula: J. Inst. Met., 76 (1949-50), 321.

26) J. Cisse, H. W. Kerr and G. F. Bolling: Metall. Trans., 5 (1974), 633.

27) F. A. Crossley and L. F. Mondolfo: Trans. AIME, 3 (1951), 1143.

28) L. F. Mondolfo: "Grain Refinement in Castings and Welds", Conf. Proc., Oct. 1982, AIME, St. Louis, (1983), 3.

29) W. A. Tiller, K. A. Jackson, J. W. Rutter and B. Chalmers: Acta melall., 1 (1953), 428.

30) P. G. Shewmon: Transformations in Metals, McGrawHill, New York, (1969).

31) C. Zener: J. Appl. Phys., 20 (1949), 950.

32) F. Hasan, G. W. Lorimer and N. Ridley: J. Phys. Colloq., 43 (1982), C4-653. 